\title{
Innovation in Tourism: "Attractor" Model as a Good Opportunity to Increase Economic Cooperation in the Balkans
}

\author{
Besarta Vladi \\ PhD candidate, European University of Tirana \\ besarta.vladi@uet.edu.al
}

Doi:10.5901/ajis.2014.v3n4p119

Abstract

Innovation is a necessity in all fields and sectors, with the main purpose to create, maintain and improve the image of a company (in microeconomic terms), and a country (in macroeconomic terms). Competitiveness and innovation are now transformed into an inseparable binomial to achieve success. Up to 10 years ago, foreign visitors have questioned the image of Albania because of different reasons, such as slow economic development, a social structure that is not fully consolidated, public institutions that are not very conscious about the role they should play in the community, private companies often oriented towards short- and medium-term plans and benefits, and so forth. There is almost the same case with the image of Kosovo. On the other hand, Montenegro and Macedonia seem to always have had a positive image, which has been more stable but still incomparable to other countries, such as Italy, Greece (despite the recent crisis) and Turkey, with respect to tourism. Given that for countries like Albania, Kosovo, Montenegro and Macedonia tourism is among the core sectors contributing towards future economic growth, there is an open discussion on how to find ways for increasing the economic cooperation among those countries in the sector of tourism. The focus of this article is a deep analysis regarding the positive impact that can be generated from the implementation of the "Attractor based model" in the sector of tourism, as an innovative model that can improve economic cooperation and quality of tourism in the Balkans (Albania, Kosovo, Macedonia and Montenegro).

Keywords: tourism, innovation, attractor-based model

\section{Introduction}

Tourism has a crucial impact on the economic growth of a country. Based on the potential of a country to develop tourism (coastal tourism, green tourism, mountain tourism etc.), we can calculate the impact of the tourism sector on the real GDP of that country. Regarding the contribution of tourism on the levels of GDP, the United Nations World Tourism Organization (UNWTO) states that this contribution differs between countries and it depends mainly on the stage of development of each of them. Specifically, in developed countries tourism counts for about $40 \%$ of the GDP, while in developing countries its contribution reaches 70\% of the GDP (Ashley et al, p.8).

This paper focuses mainly on the development of coastal and mountain tourism, which is highly favored for countries such as Albania, Montenegro, Kosovo and Macedonia, owing to their geographical position. The first part of this paper discusses about the importance of tourism to the economy of a country. The second part focuses on analyzing "The attractor based model of innovation systems", originally designed by Jan Mattsson, Jon Sundbo and Christjan Fussing-Jensen in 2006. The main contribution of this paper is to propose a new model on the development of tourism, especially coastal and mountain tourism, in Albania, Montenegro, Kosovo and Macedonia, as well as on strengthening their cooperation in this sector. The hypothesis of this paper is that the more the "Attractor based model" is implemented, the higher will be the level of economic cooperation and the number of visitors in these countries, and consequently, the higher will be the economic growth. This is a comparative study that aims to analyze the advantages of implementing the above model in Albania, Kosovo, Montenegro and Macedonia, as a good change for the economic progress in those countries.

\section{Tourism and its Impact on the Economic Growth}

The role of tourism in the economy is explicit and implicit in the same time in several ways. Firstly, the development of tourism directly increases the level of income in GDP, directly and indirectly reducing the poverty in the country. Secondly, a developed tourism sector means higher chances for job creation, thus reducing unemployment rates in the 
country. Thirdly, "mouth-to-mouth" marketing done by foreign visitors to their network can serve as a powerful tool for improving the image of recently visited countries. A positive image attracts numerous new tourists (visiting for the first time a country) and foreign investors as well. Nevertheless, for the tourism sector to be transformed into an engine of economic development, even though in short and medium term, there are several requirements to be fulfilled prior that. Tourism development demands a developed infrastructure and, above all, a qualified and qualitative staff in providing tourist services.

Albania, Kosovo, Montenegro and Macedonia are currently under the pressure of countries with similar natural resources but with considerably more developed service sector. Nevertheless, tourism in Montenegro and in Macedonia originates earlier on time compared to tourism in Albania and Kosovo. Even though the last two countries have had in the last 5 years several strategies, particularly Albania with its clear and detailed strategy for the tourism development "Sectorial Strategy of Tourism 2007-2013", the differences are still obvious. For example, Montenegro has a long tradition in tourism, with investments in this sector dating back to 1960. For two of these countries, namely Albania and Montenegro, the coastal tourism is the dominant form of tourism. On the other hand, for Kosovo and Macedonia, mountain tourism is more developed and, since they are landlocked countries, costal tourism is not an option. In addition, 'Ulcinj Spatial Plan 2020' shows a clear strategy of sectorial development of tourism in Montenegro, thus giving a clear hint that tourism will continue to be one of the dominant sectors in the economy of the country, at least for the next six years.

The tourism sector in Albania has suffered from periodic shocks, where the first one can be considered the delayed start, just after 1990. Other shocks include various economic and political events, such as the 97's crisis, 99's War of Kosovo, the prolonged transition etc. Montenegro and Macedonia have also suffered from several events that have negatively affected their images as touristic destinations. Kosovo can be considered a true "newborn" touristic destination, in contrast to the other three countries, considering tourism developments only after the war ended. Tourism is an attractive investment opportunity for investors since it offers a relatively high rate of return on investment and as well as a short payback period in terms of initial investment. Nevertheless, investors accept risk to certain limits, particularly from the legal perspective (ownership and property regulations). Unfortunately, this is an unsolved problem for Albania and even Kosovo, and partially solved for Montenegro and Macedonia.

Macedonia and Montenegro has actually well-established star rating systems of hotels. This is a significant help for visitors who want to visit these countries. On the other hand, Albania does not apply a genuine star rating system for hotels. Therefore, every tourist must satisfy his/her concerns with the information collected from web-search. In most of Albanian hotels, there is a "self-established" ranking system, when each hotel decides its own starts based on the preference of its owner(s). Probably they are not aware that they act against the law.

In 2012, thanks to the collaboration of Albanian Association of Tourism and Ministry of Culture with the USAID program, the system of hotel star rating became possible. Approximately 100 inspections from independent experts are carried out until now. From the results of this classification, the average assessment of hotels in Albania is 'four stars'. Results show as well the hotels that have received the Quality Brand, stars and the classification of hotels based on the three level system: Gold, Silver and Bronze (Authentic Albania, 2013).

However, the touristic infrastructure in the above Balkan countries shows many problems. Overloading the tourist areas with multiple and unplanned constructions, in the tourist perspective remains a concern. The contaminations of touristic areas helps the foreign tourist to choose other touristic destinations such as Turkey, which offers better conditions with, more or less, the same costs.

Problems such as unclear property rights, chaotic management of urban areas, uncontrolled migration and rapid urbanization, non-sufficient funding for the protection and maintenance of touristic area are still some of the main obstacles for the successful development of tourism in Albania (Noti, 2009). Since 2005, tourism in Albania is ranked as one of the main priorities of the government. The government contributions mainly consist on designing of adequate legal framework for infrastructural development, such as road infrastructure. Nevertheless, the success of government is related as well with the close collaboration between public and private sector. The contribution of the private sector mainly includes the guarantee of service quality in hotels and restaurants, in order to meet tourist expectations.

Countries such as Albania, Kosovo, Montenegro or Macedonia are extremely rich in natural resources and it should serve as a strong advantage for the development of tourism in these countries. Beside the problems with property law, infrastructure, service quality, environment pollution etc., still these problems can find a solution. A serious and longterm engagement and interaction between main stakeholders (government, private sector and community) can be a good starting point towards solving these problems. But solving these problems is only the first step toward the success of tourism sectors. The next step is the generation of innovative ways to promote these touristic areas to foreign tourist 
worldwide. The concept of innovation and particularly the idea of open innovation model becomes a must in this context.

The most of Balkans' countries are rich in cultural heritage, rugged terrain, and pristine beaches. They provide fascinating views to foreign visitors. For economies like Albania, the development in the sector of tourism implies direct contribution of this sector to economic growth in the future. For many years, different governments have pointed out that tourism sector will become a key driver of economic development in Albania. There have been many incentives to make tourism a key economic driver, but probably due to lack of sufficient funding or creativity, the impact of tourism in Albanian GDP has been in most of cases insignificant.

Graph 1: The number of tourist and added value in the hotel-restaurant branch in Albania

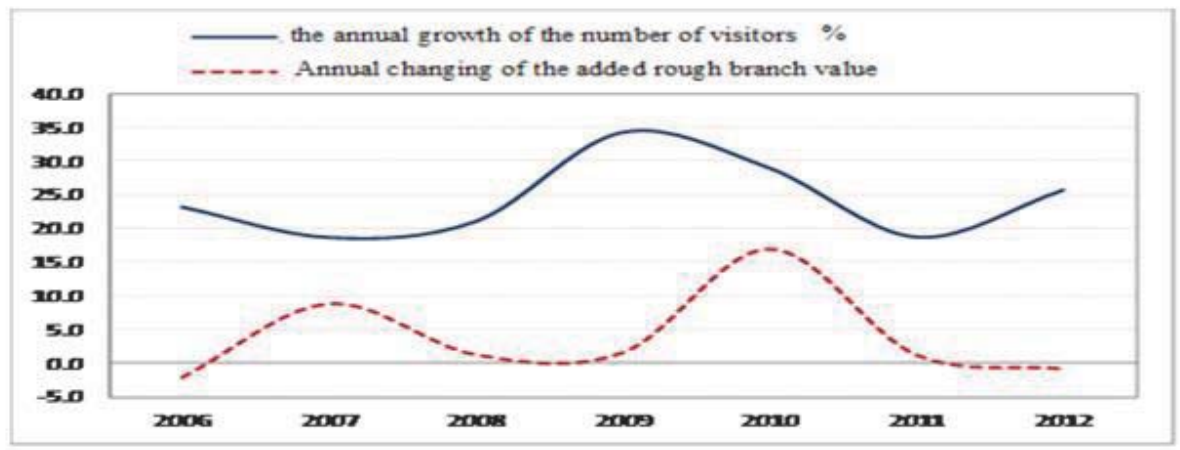

Source: The Ministry of Tourism, Culture, Youth and Sports \& INSTAT (2013)

In 2013, the direct contribution of Travel \& Tourism to GDP was ALL 68.1 billion (4.8\% of total GDP), and is forecast to rise by $5.5 \%$ in 2014 , and to rise by $5.6 \%$ per year, from 2014-2024, to ALL 123.6 billion (6.1\% of total GDP) in 2024 (WTTO Report, 2014). The total contribution of Travel \& Tourism to GDP was ALL 239.8 billion (16.7\% of GDP) in 2013 , and is forecast to rise by $4.6 \%$ in 2014 , and to rise by $5.4 \%$ per year, to ALL 424 billion (20.9\% of GDP) in 2024 (WTTO Report, 2014). In 2013, the total contribution of Travel \& Tourism to employment, including jobs indirectly supported by the industry, was $15.2 \%$ of total employment (146,500 jobs). This is expected to rise by $4.1 \%$ in 2014 to 153,000 jobs and rise by $3.2 \%$ pa to 210,000 jobs in 2024 ( $19.5 \%$ of total). Visitor exports generated ALL 154 billion ( $23.2 \%$ of total exports) in 2013. This is forecast to grow by $6.3 \%$ in 2014 , and grow by $5.6 \%$ per year, from 2014-2024, to ALL 282.5 billion in 2024 (22.2\% of total) (WTTO Report Albania, 2014, pg. 1).

Similarly, in Kosovo, as in many other countries, tourism acts as a development engine through direct impact on the GDP levels, creating employment and reducing poverty. For a "New Born" country such as Kosovo, which has just celebrated its $6^{\text {th }}$ anniversary as an independent state, the sector of tourism is highly important for the overall economic and social progress. Despite being a landlocked country, Kosovo still has great potentials to develop the sector of tourism. Actually, investments in this sector are mainly focused on restaurants construction, high quality hotels, service improvements etc. Referring to different forecasts from public or independent authorities, there are positive expectations for the role that tourism sector will play to the GDP of Kosovo, becoming the second largest sector in the economy of Kosovo.

In Macedonia, The direct contribution of Travel \& Tourism to GDP was MKD 6.7 billion (1.3\% of total GDP) in 2013, and is forecast to rise by $5.7 \%$ in 2014 , and to rise by $5.0 \%$ per year, from $2014-2024$, to MKD 11.5 billion (1.6\% of total GDP) in 2024. The total contribution of Travel \& Tourism to GDP was MKD 25.1 billion (5.0\% of GDP) in 2013, and is forecast to rise by $6.5 \%$ in 2014 , and to rise by $5.0 \%$ pa to MKD 43.5 billion (6.1\% of GDP) in 2024. In 2013 , the total contribution of Travel \& Tourism to employment, including jobs indirectly supported by the industry, was $4.5 \%$ of total employment (31,000 jobs). This is expected to rise by $4.3 \%$ in 2014 to 32,500 jobs and rise by $1.8 \%$ per year to 39,000 jobs in 2024 (5.7\% of total) (WTTO Report Macedonia, 2014, pg. 1). 
Graph 2: Tourist arrivals and night spent in Macedonia, 1958-2012

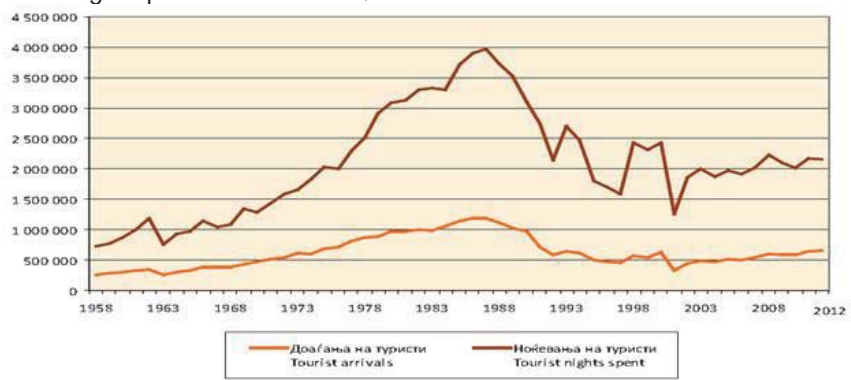

Source: Tourism in Republic of Macedonia, 1958-2012, State Statistical office (2013)

In Montenegro, The direct contribution of Travel \& Tourism to GDP was EUR 348.7 million (9.8\% of total GDP) in 2013, and is forecast to rise by $12.6 \%$ in 2014 , and to rise by $8.6 \%$ per year, from $2014-2024$, to EUR 892.4 million (17.7\% of total GDP) in 2024. The total contribution of Travel \& Tourism to GDP was EUR 714.2 million (20.0\% of GDP) in 2013, and is forecast to rise by $13.2 \%$ in 2014 , and to rise by $8.8 \%$ per annuity to EUR $1,877.3$ million $(37.2 \%$ of GDP) in 2024 . In 2013, the total contribution of Travel \& Tourism to employment, including jobs indirectly supported by the industry, was $18.3 \%$ of total employment (30,500 jobs). This is expected to rise by $14.4 \%$ in 2014 to 35,000 jobs and rise by $6.2 \%$ pa to 64,000 jobs in 2024 (34.5\% of total) (WTTO Report Montenegro, 2014, pg. 1).

Graph 3: Direct Contribution of travel and tourism to GDP 2004-2014 (Macedonia, Montenegro, and Albania)
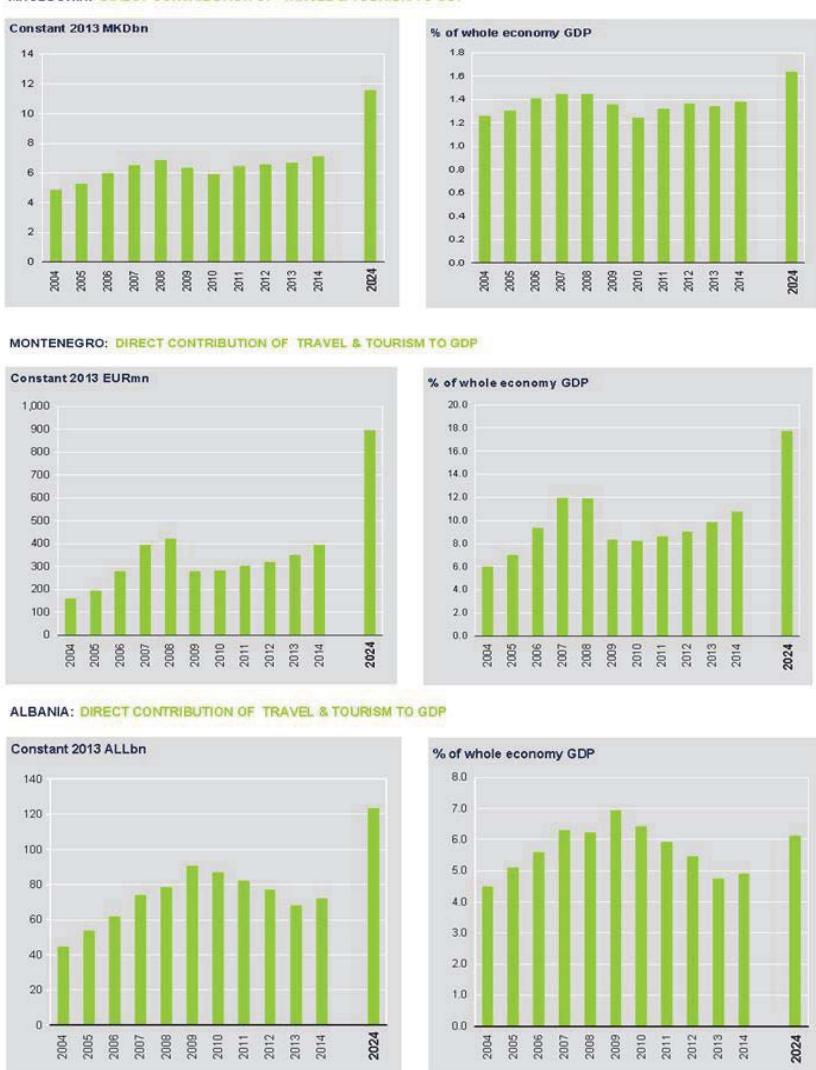

Source: World Travel \& Tourism Council (2014) 


\section{Innovation in the Sector of Tourism}

Nowadays technological progress is spreading rapidly all over the world, the same products are part of all markets, no matter how developed or underdeveloped countries they are, knowledge economy and well-educated peoples have no barriers to move from one part of the world to another and to find a job that best fulfills their expectations and ambitions. Services quality is becoming a key factor of business strategy differentiation, creating in this way a good competitive advantage in the global market. Discussing about services quality, we mainly refer to the following elements:

$\checkmark$ Modern equipment

$\checkmark$ Environment

$\checkmark$ Infrastructure/ Contemporary buildings

$\checkmark$ Automation of systems

$\checkmark$ Staff/training /communication/ willingness to serve clients

$\checkmark$ Speed of service / courtesy

$\checkmark$ The speed of problem solving / managing various situations (Bazini \& Elmazi, 2009).

Leiper (1999) claimed that tourism industry is the overall number of firms, organizations and other facilities which has their main purpose to serve to the specific needs and expectations of tourists (p. 400). Innovation can help to improve the quality of services in the tourism sector. What we mean by innovation in tourism is 'an idea, practice or object that is perceived as something new from its adopters' (Rogers 2003). Nevertheless, innovation in the service sector has an abstract character at all, because it is mainly focused on firm's experiences and their practical activities. Furthermore innovation in the service sector is considered as the 'soft' part of innovation development, by mainly focusing on skills and collaborative cross-organizational practices (Tether, 2005).

On the other hand, if we refer to European Commission Report (2004), innovation covers a wide range of activities which help firm's performance improvement, including the implementation of products, services, processes, systems and new organizational models, with the main purpose to create new customer values and to increase financial incomes of the firms. However, the huge gap in terms of studies about service innovation and tourism innovation is still an obstacle for researchers (Peters \& Pikkemaat 2006).

Innovation development (including all types of innovation), potentially generate added value to customers, but applying this general principle in the service sector (such as tourism), the situations becomes much more complex. Some of the most contemporary innovative ideas in the field of tourism will be analyzed below. Some of them probably are not applicable for none of the countries taken into consideration in this paper, but some of them can be adopted gradually in the nearest future.

The first idea consists on strengthening the cooperation between social services and tourism, considering this as a good opportunity to promote service innovation in tourism. Social services are mainly related to human capital, environment protection, discouraging destructive behavior toward environment, elaborating the concept of 'full employment', health service etc. (Hjalager 2006). Another option is given later on by Weiermair, who analyzed the concept of innovation in tourism seen from the perspective of supply. According to him, innovation in the service sector would be possible if there is sufficient funding available. The fulfillment of this requirement enables risk management of innovation process in the field of tourism. Factors such as firm size and, technological progress are necessarily associated with this process (Weiermair 2004).

Another idea is thrown around the relationship between the concepts of leadership and innovation processes, with the main focus on improving the quality of tourism services. The process of innovation in this case considered as a crossorganizational network process, similar with open innovation model (Chesbrough 2006). The main goal is the minimization of collaboration obstacles and the initiation of different activities with networking opportunities which, directly or indirectly, can be a good source for the promotion of further cooperation and innovation (Pechlaner, Fischer \& Hammann 2006).

\section{How to Increase Revenues from Tourist by using the Attractor-Based Innovation System?}

This model was designed in 2006 by January Mattsson, Jon Sundbo and Christjan Fussing -Jensen. The main assumption of this model is that tourism development in a country does not function based on a single touristic organization and its level of innovation. Conversely, it is very important to establish a broad interaction between many firms, considering them as an open network rather than a closed system. However, this idea does not mean that all touristic organizations of a country should necessarily be part of this cooperation. Another condition for the model to be 
successful is the level of cooperation between enterprises and innovation in tourism. Entrepreneurs create the necessary conditions for the emergence of innovation, because potentially they can be very skilled at creating the right social network. Therefore the enterprise considered as a prerequisite for the emergence of innovative ideas.

In this model, innovation is not a one-factorial result. Conversely it is result of various firms and organizations cross-levels interaction within a given region resort, in most cases related to the concept of 'attractor'. The components of this model are: attractor, scene, scene-maker, scene-taker, and tourist networks - touristic organizations - local organizations. In this case, 'attractor' can be an organization, event, activity that attracts initial attention and enables the participation of many people. A scientific conference for example plays a very good role as an attractor. The positive reaction of people regarding this attraction, transforms the latter one from being a simple attractor to a genuine scene of meeting between different people, in a perfect touristic place, whose initial goal was not tourism.

Fig. 1: Attractor-Based Innovation System

\section{Source: (Mattsson et al 2006)}

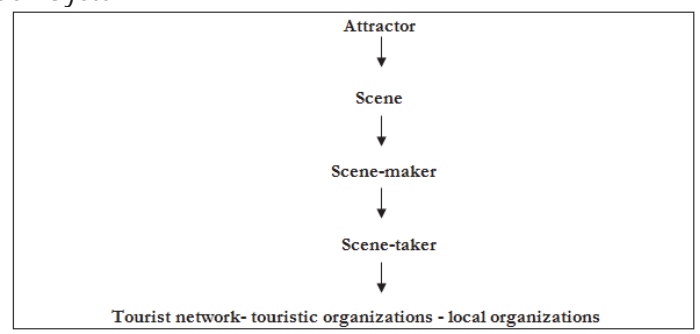

Nevertheless, the mere existence of this 'scene' is not sufficient to capture a high number of tourists in the future. This 'scene' should offer many opportunities and engagement roles to firms, organizations and local individuals. This allows them to extend their network and, at the same time, to offer various information for participants on this events. Scenemaker can be a person/ a touristic firm/ a non-touristic organization, or a group of individuals that strategically analyze all possible alternatives to gather as much visitors as possible. In this case, scene-maker is the innovator as long as it is able to create and conceptualize the scene.

The created scene should be kept active through intensive and professional marketing efforts, and though incorporation of as many collaborators as possible. At this point, we pass from the scene-maker to scene-taker, who can be an individual, a firm or an organization in the country. The last one must have entrepreneurial character, even though it is not necessarily the innovator of this new created context. Different touristic firms from many countries can benefit from the activities of scene-taker, having all opportunities to be part of this scene-taker cooperation and network. In these conditions, innovation becomes an essential element for occasionally scene renewal, in order to be always attractive for its visitors. In case nobody takes care of maintaining this scene active, then it will have no effect at all in the local tourism on that area or region in the future.

Results of Mattsson et al' study (2006) show that the number of scene-makers is high but the number of scenetakers is very low, and for this reason, the contribution of such events cannot be directly converted into a larger number of tourists. According to this model, if touristic firms have a conservative approach and do not collaborate with other organizations, in order to guarantee the 'active status' of the new created context, the whole incentive to attract new visitors will fail.

Fig. 2: An example of implementation of this model in the Balkans

Source: Author (2014)

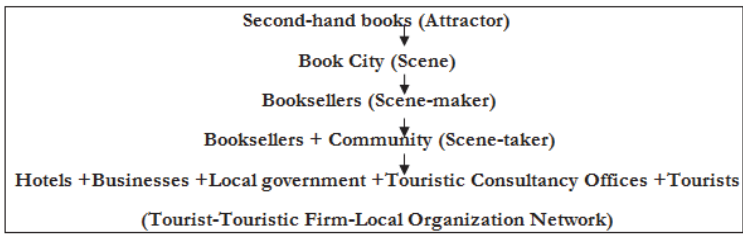


The authors of this model have achieved some important results, which serve as prerequisites for the successful implementation of this model in the Balkans. First of all, the components of this model must be all present and functional, in order for the model to work. Secondly, the basic link of this model is scene- taker because it guarantees the durability of this process. The scene itself must be designed and created before the transition from scene -maker to scene- taker. Also, if the scene-taker is present, touristic firms will have more benefits if they make a constant effort to keep this new created context well established and functional. The positive effects of attractor on increasing the number of tourists, and consequently on economic growth in the country, require strong innovation by touristic firms. It also required a strong collaboration network between firms operating in this sector.

In case this model is taken seriously by all stakeholders in Albania, Kosovo, Macedonia, and Montenegro, the positive results will be immediate. What is not mentioned in the model above but which we can add, is that the interaction cannot be narrowed only within a given region. On the contrary, there can be a very successful cooperation between neighboring countries, and especially when geographic distances are almost insignificant, either in the airline, as well as coastal. In each of the links on the above model, contributors can arise by four countries. Understandably, the so-called 'scene-taker' should probably be more engaged physically, since it will always be within the created context, but cooperation and support can be broader than the national borders of each country in which is provided the touristic service.

\section{Conclusions}

Albania, Kosovo, Macedonia and Montenegro are all rich in terms of natural beauties, favorable geographic position, stable climate etc. All these factors suggest that the tourism sector in these countries should be one of the key drivers of economic growth. Actually, the real contribution of tourism to their GDPs is at moderate levels. The Implementation of 'Attractor-based innovation system' can positively lead to a more productive use of these favorable geographic positions. The attractor's positive effects at this model are: the increased number of tourists; economic growth; open and strong innovation from touristic firms etc. This implies the establishment of a strong and consolidate cooperation network between touristic firms, government, non-touristic organizations, and other collaborators beyond the national borders.

\section{References}

Ashley et al. (2007) 'The role of the tourism sector in Expanding Economic opportunity' Economic Opportunity series: International Business Leaders Forum, Harvard University.

Bazini, E dhe Elmazi, L (2009) 'Cilësia e sherbimeve dhe marketingu i brendshëm, rasti i hoteleve bregdetare' Economicus Magazine 9, UET Press, pg. 185-192.

Chesbrough, H. (2006) 'Open Innovation: A new paradigm for understanding industrial innovation' Oxford; Oxford University Press

Hjalager, A (2006) 'Stages in the economic globalization of tourism' Elsevier Itd. Annals of Tourism Research, Vol. 34, No. 2, pg. 437457

Ivanovic, M (2010) 'Menadzment ljudskih resursa u hoteljierstvu Cmogorskog primorja' Novi Sad.

Jan Mattsson , Jon Sundbo \& Christjan Fussing-Jensen (2006): Innovation Systems in Tourism: The Roles of Attractors and SceneTakers, Industry and Innovation, 12:3, 357-381

Leiper, N. (1999) Are destinations the heart of tourism?, Current Issues in Tourism, 4, pg. 390-407.

Mike Peters \& Birgit Pikkemaat (2006): Innovation in Tourism, Journal of Quality Assurance in Hospitality \& Tourism, 6:3-4, 1-6

Ministry of Culture, Tourism, Youth and Sports (2013) 'Statistical indicators about tourism 2011' Tiranë.

Noti, E. (2009) 'Politikat Strategjike per zhvillimin e turizmit ne Shqiperi' Economicus 9, Tiranë.

Pechlaner, H , Fischer, E \& Hammann, E (2006): Leadership and Innovation Processes-Development of Products and Services Based on Core Competencies, Journal of Quality Assurance in Hospitality \& Tourism, 6:3-4, 31-57

Rogers, E (2003) 'Diffusion of Innovation', Free Press, Fifth Edition, New York

Statistical Office of Montenegro (2013) 'Number of tourist arrivals and overnight stays 2008-2012' url: http://www.monstat.org/eng /page.php?id=1097\&pageid=44 (Last time viewed: 5/11/2014).

Tether, B. S. (2005) Do services innovate (differently)?, Industry and Innovation, 12(2), pg. 153-184.

Weiermair, K (2004) 'Product improvement or innovation: what is the key to success in tourism?' University of Innsbruck, OECD, pg. 111

World Travel \& Tourism Council (2014) travel and Tourism: Economic Impact 2014 (Albania, Macedonia, Montenegro. UK 
